\title{
British Society of Gastroenterology
}

Dr John Bennett grew up in Merseyside and graduated from Liverpool University. Following a short flirtation with microbiology he was attracted to gastroenterology by Dr Trevor Cooke while training in general medicine at the General Hospital, Birmingham. Two years as Sheldon Research Fellow with Dr Michael Atkinson in Worcester studying oesophageal pain led to a year with $\mathrm{Dr}$ T R Hendrix at the Johns Hopkins Hospital, Baltimore, and firmly established the oesophagus as his lifelong interest.

The opportunity to design and establish a new gastroenterology unit serving a large but stable population took him in 1969 to Kingston upon Hull where he has continued to practise clinical gastroenterology with general medicine. Convinced that high quality medicine can be available in all district hospitals, he has, with his colleagues (and despite continual NHS crises), developed contemporary gastroenterology. $\mathrm{He}$ has maintained a productive research interest, particularly in the fields of oesophageal disease and therapeutic endoscopy.

Dr Bennett has also contributed to the medical literature by editing two editions of Therapeutic endoscopy and radiology of the gut (1979 and 1990), Practical problems in gastroenterology (1985), and Reflux oesophagitis (1984). He was Chairman of the Medical Writers Group of the Society of Authors 1988-90.

Dr Bennett's energetic, cheerful, and optimistic personality has been a constant feature of his many contributions to the BSG. As Treasurer of the BSG (1979-84) he helped to negotiate a new contract for the Society's journal. Later he was Vice President (Endoscopy) 1985-87, and Chairman of the Oesophageal Section 1988-89. He was President of the North of England Gastroenterology Society 1979-81. Dr Bennett was elected Treasurer of the European Gastroenterology Organisation ASNEMGE in 1988, reflecting his enthusiasm for the development of a United European Gastroenterology Week.

On the wider medical scene he served on the Merrison Committee on Regulation of the Medical Profession (1973-75) and was Chairman of the Campaign on the Use and Restriction of Barbiturates $(1976-78)$. His experience on the Merrison Committee led him to stand for election to the General Medical Council on which he is serving a second term.

Dr Bennett has had an interesting relationship with the Royal College of Physicians of London, on the one hand serving on its Council and as Secretary to its Working Party on Audit, while on the other ruffling feathers in an unsuccessful campaign to have the President democratically elected by postal ballot.

He has been a member of the Council of the University of Hull since 1978, where he has encouraged the development of its postgraduate medical institute.

His occasional leisure time is occupied with music, literature and, with advancing years, a transition from dinghy sailing to gardening. 